\title{
Effect of black tea drinking on blood lipids, blood pressure and aspects of bowel habit
}

\author{
BY S. A. BINGHAM ${ }^{1}$, H. VORSTER ${ }^{2}$, J. C. JERLING ${ }^{2}$, E. MAGEE ${ }^{1}$, A. MULLIGAN ${ }^{1}$, \\ S. A. RUNSWICK ${ }^{2}$ AND J. H. CUMMINGS ${ }^{1}$ \\ ${ }^{1}$ Medical Research Council, Dunn Clinical Nutrition Centre, Hills Road, Cambridge CB2 2DH \\ ${ }^{2}$ Department of Nutrition, Potchefstroom University for Christian Higher Education, Potchefstroom, \\ South Africa
}

(Received 3 September 1996 - Revised 27 November 1996 - Accepted 13 December 1996)

\begin{abstract}
Thirty-one men (47 (SD 14) years) and thirty-four women (35 (SD 13) years) took part in a 4-week randomized cross-over trial to compare the effect of six mugs of black tea daily $v$. placebo (water, caffeine, milk and sugar) on blood lipids, bowel habit and blood pressure, measured during a run-in period and at the end of weeks 2,3 and 4 of the test periods. Compliance was established by adding a known amount of $p$-aminobenzoic acid (PABA) to selected tea bags, and then measuring its excretion in urine. Mean serum cholesterol values during run-in, placebo and on tea drinking were 5.67 (SD 1.05), 5.76 (SD 1.11) and 5.69 (SD 1.09) $\mathrm{mmol} / \mathrm{h}(P=0 \cdot 16)$. There were also no significant changes in diet, LDL-cholesterol, HDL-cholesterol, triacylglycerols, and blood pressure in the tea intervention period compared with placebo. Compared with placebo, stool consistency was softened with tea $(P=0 \cdot 04)$, and no other differences were found in bowel habit. Results were unchanged when fifteen 'non-compliers', whose PABA excretion indicated that fewer than six tea bags had been used, were excluded from the analysis, and when differences between run-in and tea periods were considered separately for those who were given tea first or second.
\end{abstract}

Tea: Blood lipids: Cardiovascular disease

The major constituents of tea are polyphenolic flavonoids $(250-350 \mathrm{~g} / \mathrm{kg}), \mathrm{NSP}(300 \mathrm{~g} / \mathrm{kg})$ together with physiologically-active alkaloids and small amounts of carbohydrate, protein, vitamins and minerals. The polyphenolic flavonoids in green tea are mainly the flavanols epicatechin, epigallocatechin and their gallate esters but include the flavonols quercetin and myricetin (Graham, 1992; Hertog et al. 1993). During fermentation in the preparation of black tea, some oxidative polymerization of the polyphenols occurs with the formation of theaflavin, theaflavin gallates, epitheaflavic acids and thearubigens. Up to $100 \mathrm{~g} / \mathrm{kg}$ dry weight of black tea extracted solid may comprise unoxidized catechins, with $30-60 \mathrm{~g}$ theaflavins $/ \mathrm{kg}$ and $120-180 \mathrm{~g}$ thearubigens $/ \mathrm{kg}$ (Graham, 1992).

The possible effects of green-tea polyphenols in reducing cardiovascular disease risk factors have been the subject of much interest. In experimental hypercholesterolaemia, green tea has been found to reduce serum cholesterol (Matsuda et al. 1986; Muramatsu et al. 1986; Hara, 1992). Tea catechins decrease intestinal absorption of cholesterol in rats (Ikeda et al. 1992). A Japanese cross-sectional epidemiological study has shown significant inverse relationships between green tea consumption and serum cholesterol and HDL and LDL levels (Imai \& Nakachi, 1995). Furthermore, tea polyphenols have strong antioxidant properties. They are metal ion chelators, scavengers of superoxide and $\mathrm{OH}^{-}$, and able to terminate lipid peroxidation chain reactions (Yang \& Wang, 1993). Polyphenolic 
compounds in tea could, therefore, have other protective roles in CHD since free radical activity is currently thought to be important in the generation of oxidized LDL particles (Steinberg et al. 1989). Green-tea polyphenols have been found to reduce blood pressure in spontaneously hypertensive rats (Hara, 1992).

However, in some countries including the UK, tea is drunk as black tea with milk added, and the present study was designed to test the hypothesis that black tea as commonly consumed might alter blood cholesterol levels and another cardiovascular disease risk factor, blood pressure. A Danish study has also suggested that severe constipation was related to the daily tea consumption of 1 or 2 litres (Hojgaard et al. 1981), so the opportunity was taken to observe changes in bowel habit. Sixty-five subjects took part in a 10-week crossover study comparing the drinking of six or more mugs of black tea daily with a placebo in two 4 -week periods, after a 2 -week run-in period. To exclude the potential effects of caffeine, caffeine tablets were included in the placebo group, together with each individual's usual amount of milk and sugar, and an equivalent amount of water. Compliance with the protocol was assessed using $p$-aminobenzoic acid (PABA) incorporated onto tea bags.

\section{METHODS \\ Protocol}

The 10 -week study was divided into a 2 -week run-in period, 4 weeks with tea and 4 weeks without tea. Each volunteer visited the Dunn Clinical Nutrition Centre (DCNC) weekly by appointment. Throughout the course of the study, measurements were made of diet, fluid intakes, bowel habit, weight, blood pressure, and blood and urine were collected. From week 6 onwards smokers were required to fill in a weekly smoking assessment slip, giving details of the number of cigarettes or amount ( $\mathrm{g}$ ) of tobacco smoked daily. Volunteers were given weekly information diaries reminding them to complete food and bowel-habit diaries and to follow other instructions.

\section{Recruitment}

A pilot study was carried out on eight subjects in order to assess the feasibility of questionnaires and diaries that were created especially for the study. It was also necessary to test the feasibility of PABA-impregnated tea bags. Volunteers for the pilot study were recruited by placing notices advertising the study in the DCNC. The volunteers who participated, with the exception of one male who was a member of the general public, were all staff working at the DCNC. All results from the pilot study were used.

An advertisement was then placed in a local newspaper in November 1992 in order to recruit volunteers for the rest of the study. Seventy-nine of the 105 people who responded attended medical examinations, which included a standard questionnaire before the study and urine, blood lipids, height, weight and blood pressure measurements. Volunteers were excluded if they were substantially obese $\left(B M I>35 \mathrm{~kg} / \mathrm{m}^{2}\right)$, diabetic, pregnant or suffering from a known lipid or thyroid disorder or were taking blood pressure drugs, anticoagulants or regular laxatives. Alcoholics and serious slimmers were also excluded from the study. After detailed explanations, all subjects gave informed consent to the study protocol, which was passed by the Ethical Committee of the Dunn Nutrition Unit in October 1992. Using the results from the initial medical examination, subjects were matched for age (by 10-year bands), sex and initial cholesterol (by $1 \mathrm{mmol}$ bands), then randomly assigned to first presentation of tea or placebo periods. Twenty respondents were unsuitable, due to medical 
reasons or an inability to commit themselves. Two volunteers who commenced the study failed to complete it due to personal reasons, leaving fifty-seven to participate in the second phase of the study.

\section{Run-in period}

The 2-week run-in period was used to establish baseline data for habitual dietary intake, normal bowel habit, weight, blood pressure and serum lipids. During this time, volunteers followed their daily routine and were asked to complete a $7 \mathrm{~d}$ dietary diary and the $14 \mathrm{~d}$ bowel-habit diary (see p. 44).

\section{Tea period}

A minimum intake of six tea bags daily (twice the national average) was to be taken in the protocol; each tea bag to be prepared in a standard mug on which a DCNC logo was printed. Participants were instructed to follow a standardized protocol in which each bag was left in the standard $300 \mathrm{ml}$ mug of boiling water for $1 \mathrm{~min}$, and the bag was prodded six times and squeezed well against the side of the mug before removal. This procedure was designed to obtain maximum polyphenol contents per mug, and to minimize variability in PABA content (see p. 45). Milk was added as normal before drinking. If subjects normally drank more than six cups per $d$ they were permitted to take more than the minimum in order to maximize compliance. The tea was a special World Blend prepared for the study by the Tea Packer's Association and designed to reflect the relative proportions of teas imported into the UK. Caffeine was measured after hot-water extraction and reversedphase HPLC (Lyons Tetley, personal communication). The caffeine content per $300 \mathrm{ml}$ mug following this protocol was $80 \mathrm{mg}$.

\section{Placebo}

The placebo was matched to water, milk, sugar and caffeine intake. To match the estimated 1.5 litres water from six mugs of tea, each subject was provided with 1.5 litres (or more) bottled water on the first day of the non-tea-drinking period. Subjects then refilled their bottle with tap water each day for the remainder of the study. During this period, subjects were not allowed any other drinks except coffee, intake of which was standardized. To assist compliance with the study protocol, fruit 'tea' was allowed and this was taken by two volunteers.

To adjust for milk in the placebo, subjects were asked to pour into a mug the amount of milk they would normally drink in a mug of tea. This amount was measured, increased at least sixfold (depending on individual intake of tea bags) and poured back into the mug. A mark was placed on the outside of the mug to indicate the volume of milk which should be consumed by each volunteer per day, and the volunteers were instructed to drink this amount. Volunteers were also given an equivalent amount of boiled sweets to compensate when necessary for the estimated amount of sugar consumed.

In order to maintain a constant intake of caffeine throughout the study, each subject received a vial containing at least ten $50 \mathrm{mg}$ caffeine tablets (Roche Nicholas Consumer Healthcare, Welwyn Garden City, Herts.) per d, which was the amount equivalent to the six or more mugs of tea to be consumed $(500-900 \mathrm{mg} / \mathrm{d})$. 


\section{Diet diaries and records of drinks}

Volunteers were asked to record their habitual food and drink intake in a $7 \mathrm{~d}$ dietary diary (Bingham et al. 1994), during the run-in period and last week of each experimental period. Each subject was requested to consume an identical diet in week 10 to that recorded in week 6. Diaries completed in week 6 were returned to the subjects in week 10 , accompanied by a fresh diary. The diaries were analysed using a computerized program, DIDO (Data In, Diet Out; F. Key, A. Paul, A. Harter, G. Price, T. Cole and M. Wadsworth, unpublished results), based on the 4th edition of McCance and Widdowson's The Composition of Foods with cereal and diary product supplement values, and with additions for NSP (Paul \& Southgate, 1978; Wiles et al. 1980; Holland et al. 1988, 1989; Bingham et al. 1990). Fatty acids were calculated using a 'look up' table from the 5 th edition of McCance and Widdowson's The Composition of Foods (Holland et al. 1991). To assist compliance with the study protocol and avoid caffeine withdrawal symptoms (Silverman $e t$ al. 1992), coffee drinking during the experimental periods was standardized at one to three mugs daily for those who normally drank coffee. A standard blend of coffee was supplied by the UK Tea Packers' Association. Volunteers who did not normally consume coffee were not expected to consume any during the 8-week study period. Volunteers recorded the number of cups, glasses and mugs of drinks consumed daily throughout the tea and placebo periods in a separate booklet.

\section{Bowel habit}

Volunteers were required to complete a $14 \mathrm{~d}$ bowel-habit diary devised for use in the study and at Addenbrooke's Hospital Gastroenterology Department during the run-in period and for the last 2 weeks of each test period. The subjects' reports of bowel habit provided baseline data for frequency (numbers of specimens in $14 \mathrm{~d}$ ), size (scoring 1, 2, 3 for small, medium, large, respectively) and consistency (scoring 1,2, 3 for hard, soft and loose; Magee, 1993). Time (min) per bowel movement was recorded.

\section{Weight and blood pressure}

Weight and blood pressure measurements were made at the beginning of the study and on a weekly basis from then on. Weight $(\mathrm{kg})$ was measured without shoes and jackets at the DCNC. Blood pressure was measured also at the DCNC by trained nurses using a standardized protocol with the volunteer lying down with arm supported on the bed, after a 3 min rest. Each participant's blood pressure was measured on the same arm by the same nurse throughout the study using the same standard $\mathrm{Hg}$ sphygmomanometer (Dekamet MK2; Thackray, Leeds) and auscultatory measurement as follows: systolic, when sound first appears for at least two beats; diastolic, when repetitive sounds become muffled, phase 4. Both were recorded to the nearest $2 \mathrm{~mm} \mathrm{Hg}$ on a weekly sheet by subject number, blinded to treatment period. Random zero sphygmomanometers were not used due to incompatibility with results from conventional methods (O'Brien et al. 1990; Lawson et al. 1991).

\section{Blood collection and analysis}

Each volunteer gave a $10 \mathrm{ml}$ blood sample at the DCNC at the time of the initial medical, at the end of the 2-week run-in period and at the end of the $2 \mathrm{nd}$, 3rd and 4 th weeks of each 
test period. Blood was taken in monovettes after a $12 \mathrm{~h}$ fast and with as little compression as possible. Serum was stored at $-20^{\circ}$ before analysis for blood lipids. Cholesterol and triacylglycerols were measured after enzymic hydrolysis of the esters and triacylglycerols, then oxidation to $\mathrm{H}_{2} \mathrm{O}_{2}$ and measurement of the indicator quinoneimine. HDL-cholesterol was measured by precipitation of LDL, VLDL and chylomicrons with phosphotungstic acid, and LDL-cholesterol was calculated from the formula: LDL-cholesterol $(\mathrm{mmol} / \mathrm{l})=$ total cholesterol - (triacylglycerols/2.2) - HDL-cholesterol. Randox packs (Randox Laboratories Ltd, Crumlin, Northern Ireland) were used for all these analyses using the Roche Cobas Fara system (Roche Products Ltd, Welwyn Garden City, Herts.).

\section{Urine}

Volunteers were asked to carry out two $24 \mathrm{~h}$ urine collections in the last week of the run-in, placebo, and tea periods. In the run-in and placebo periods, they were asked to take PABAcheck tablets (Laboratories for Applied Biology, London) whilst making the collections, and in the tea period, PABA was incorporated onto tea bags to check compliance (see below).

The procedure for making $24 \mathrm{~h}$ urine collections was explained in detail, when the importance of reporting any errors in making urine collections was stressed. Subjects were given a 2.5 or 5.0 litre container containing 2.5 or $5.0 \mathrm{~g}$ boric acid as preservative, a jug and printed instructions. A foil strip containing three $80 \mathrm{mg}$ PABAcheck tablets was provided for the run-in and placebo collections and the importance of reporting errors in taking the PABAcheck tablets was stressed. The subjects were asked to record the time of the start and finish of the collection on a questionnaire, together with any lost specimens, medications and problems, and in placebo and run-in periods, the time of taking the PABA tablets. The total weight of the collection was recorded and portions stored at $-20^{\circ}$ before analysis by previously described methods (Bingham \& Cummings, 1983; Bingham et al. 1988). Volunteers were asked not to take any drugs or vitamins known to interfere with the assay used to measure PABA concentration (Bingham \& Cummings, 1983). Recoveries in excess of $115 \%$ administered PABA, indicative of interfering drug consumption, were excluded from analysis.

\section{Compliance}

Compliance with the tea drinking was monitored by $24 \mathrm{~h}$ urine recovery of the urine marker PABA. For the first 3 weeks of the tea drinking period, subjects were given six marked tea bags on three random days. In the last week, $2 \mathrm{~d}$ of tea bags were given to coincide with urine collection days. The sides of each of the six tea bags were impregnated with $100 \mu \mathrm{l}$ solution containing $27 \mathrm{mg}$ PABA as $35 \mathrm{mg}$ of the potassium salt, which is equivalent to $162 \mathrm{mg}$ PABA$/ \mathrm{d}$. The tea bags were then left to dry overnight and used within 10-14 d. On the urine collection days, subjects were asked to record the time of the start and finish of the collection on a questionnaire, together with the time of taking the tea bags, any lost specimens, medications and problems. Equipment provided for all urine collections made during the test periods and analysis of PABA in urine was as described previously. Compliance was assessed by comparison of $24 \mathrm{~h}$ urine PABA, with the expected value of $162 \mathrm{mg}$. Preliminary studies established that in reliable volunteers, urine recovery from PABA from these impregnated tea bags was $92 \%$ (CV 6\%) which is not different from that expected from PABAcheck tablets (Mulligan, 1993). 


\section{Statistics}

To determine power to detect differences in means, data on average blood cholesterol levels $(5.8 \mathrm{mmol} / \mathrm{l})$ were used from a national survey (Gregory et al. 1990), assuming a $10 \%$ within-person CV in serum cholesterol levels (Gardner \& Heady, 1973; S. A. Bingham, A. Cassidy, T. J. Cole, A. Welch, S. A. Runswick, A. E. Black, D. Thurnham, C. Bates, K. T. Khaw, T. J. A. Key \& N. E. Day, unpublished results). In paired analysis, sixty subjects would be sufficient to detect a $5 \%$ difference in cholesterol $(0.29 \mathrm{mmol} / \mathrm{l})$ between test and placebo, setting $\alpha 0.05, \beta 0.20$ (Armitage \& Berry, 1987). The averaged data obtained over the different weeks (from 1 to 4 weeks depending on the protocol) from each participant were used to calculate mean and standard deviations of results for run-in, tea and placebo periods shown in the tables. Paired $t$ tests were carried out on these values. Where 1 week's data were missing for blood pressure and lipids, the average of the other 2-3 weeks was taken in the tea and placebo periods. Analyses on matched separate weeks in placebo and tea periods were also carried out where indicated in the text. To check for carry-over effects, unpaired $t$ tests were conducted on differences between serum lipids obtained in the 4th week and the run-in period in the thirty-four subjects who were given tea first, and thirty-one subjects who were given tea after cross-over in the protocol. $t$ tests and all other analyses were conducted using Systat 5.2 (Systat, 1990-2).

\section{RESULTS}

\section{Participants}

Eight volunteers (three males, five females) were recruited for the pilot study, and fiftyseven of the recruits from the main study completed it. Hence, sixty-five subjects took part in the randomized, placebo-controlled cross-over study. Thirty-one men and thirty-four women, mean age 40 (SD 15; range 20-73 years) participated. Except where otherwise stated, all followed their daily routine.

Findings from the initial examination are summarized in Table 1. Compared with a national sample (Gregory et al. 1990), there were no significant differences in anthropometric measures or blood pressure in males, although the volunteer women were slightly taller and had a lower BMI. Initial serum cholesterol levels ranged from 3.9 to $8.1 \mathrm{mmol} / \mathrm{l}$. There were no significant differences in either sex between mean serum cholesterol values and those obtained in the national sample. Compared with the national sample, the volunteers usually drank more cups of tea and less coffee (Table 1).

\section{Diet, smoking and body weight}

Table 2 shows intakes of nutrients calculated from diaries kept in the run-in, placebo and tea-drinking periods. There were no significant differences observed in the consumption of the major nutrients, nor in fatty acid intakes between the tea and placebo periods. Differences remained non-significant when data from non-compliers (see p. 47) were excluded from the analysis (data not shown).

There were twenty-four smokers in the study and they smoked approximately eleven cigarettes per $d$ with no changes between placebo and tea periods (Table 2). Table 2 shows average body weight values over the 4 weeks for all subjects and when non-compliers were excluded. Overall, there was a borderline significant difference in weight between placebo and tea periods $(P=0.051$ for all subjects) and this became non-significant $(P=0.138)$ when non-compliers were excluded. 
Table 1. Characteristics of sixty-five participants measured in the initial medical examination compared with a national sample of randomly-selected 16-64-year-old adults (Gregory et al. 1990)

(Mean values and standard deviations)

\begin{tabular}{|c|c|c|c|c|c|c|c|c|}
\hline \multirow{3}{*}{$n \ldots$} & \multicolumn{4}{|c|}{ Present study } & \multicolumn{4}{|c|}{ Gregory et al. (1990) } \\
\hline & \multicolumn{2}{|c|}{$\begin{array}{c}\text { Men } \\
31\end{array}$} & \multicolumn{2}{|c|}{$\begin{array}{c}\text { Women } \\
34\end{array}$} & \multicolumn{2}{|c|}{$\begin{array}{l}\text { Men } \\
1160 \dagger\end{array}$} & \multicolumn{2}{|c|}{$\begin{array}{c}\text { Women } \\
1163 \dagger\end{array}$} \\
\hline & Mean & SD & Mean & SD & Mean & SD & Mean & SD \\
\hline Age (years) & 47 & 14 & 35 & 13 & & & & \\
\hline Height (m) & 1.76 & 0.08 & $1.65^{* *}$ & 0.05 & 1.74 & 0.07 & 1.62 & 0.07 \\
\hline Wt $(\mathrm{kg})$ & $78 \cdot 0$ & 10 & 63.2 & $6 \cdot 2$ & 75.9 & 11.6 & $64 \cdot 3$ & $13 \cdot 3$ \\
\hline BMI $\left(\mathrm{kg} / \mathrm{m}^{2}\right)$ & $25 \cdot 1$ & $2 \cdot 5$ & $23 \cdot 3^{*}$ & 2.4 & $24 \cdot 9$ & 3.8 & $24 \cdot 6$ & $5 \cdot 1$ \\
\hline $\mathrm{SBP}(\mathrm{mm} \mathrm{Hg})$ & 130 & 19 & 119 & 12 & 125 & 13 & 118 & 17 \\
\hline Serum cholesterol $(\mathrm{mmol} / \mathrm{l})$ & $6 \cdot 0$ & $1 \cdot 1$ & 5.5 & $1 \cdot 1$ & $5 \cdot 8$ & 1.2 & $5 \cdot 8$ & 1.4 \\
\hline Tea (cups per d) & $6 \cdot 6$ & $4 \cdot 3$ & $4 \cdot 1$ & $2 \cdot 6$ & $3.2 \ddagger$ & - & $3.0 \ddagger$ & - \\
\hline Coffee (cups per d) & 1.5 & 1.4 & $1 \cdot 7$ & $2 \cdot 2$ & $2 \cdot 4 \ddagger$ & - & $2 \cdot 7 \ddagger$ & - \\
\hline
\end{tabular}

SBP, systolic blood pressure.

Mean values for the volunteers were significantly different from those for national sample: ${ }^{*} P<0.01, * * P<0.001$.

$\dagger$ Calculated from published values for standard errors, baseline values vary; e.g. 923 and 809 for serum cholesterol values.

$\ddagger$ Values for consumers only, assuming average cup is equal to $190 \mathrm{~g}$ (Crawley, 1988).

\section{Tea consumption and compliance measures}

Table 2 shows that the average daily intake of tea, reported from the questionnaires during the run-in period, was 1.44 litres/d, which increased to an overall mean intake of 1.97 litres/d during the tea period. Coffee drinking remained relatively constant throughout the 10 -week study at a mean daily volume of 0.43 litres/d (data not shown). The average daily number of tea bags used during the tea period ranged from six to seventeen (mean 6.6 (SD 1.72)). There were also no significant differences in total drinks consumed (Table 2).

Table 2 also shows mean PABA recoveries and urine volumes from the $24 \mathrm{~h}$ urine collections in each of the run-in, placebo and tea periods. There were no significant differences in urine volumes between the tea and placebo periods. Mean PABA recoveries (including incomplete collections) obtained from collections whilst PABAcheck tablets were being taken were similar in the run-in and placebo periods (88 (SD 14) \% and 84 (SD $17) \%$ respectively). However, significantly lower recoveries of PABA were found in the tea period $(76($ SD 21.0$) \% ; P=0.046)$.

With the knowledge that each tea bag contained $27 \mathrm{mg}$ PABA, compliance on an individual basis was assessed from the recovery of PABA in urine, making the necessary assumption that the $24 \mathrm{~h}$ collections were complete. Of the $13024 \mathrm{~h}$ collections made in the tea period, fifty-six collections contained PABA equivalent to six tea bags per $d$ and forty-two collections contained the equivalent of four to five tea bags per $\mathrm{d}$. Hence, ninetyeight or $75 \%$ of collections contained the equivalent of at least four tea bags per d. A total of thirteen collections contained PABA equivalent to the intake of only one or two tea bags per $\mathrm{d}$. On this basis fifteen subjects were judged poor compliers to the study protocol because their average PABA recovery from both $24 \mathrm{~h}$ collections was $<66 \%$ of the expected PABA, equivalent to less than four tea bags per $\mathrm{d}$. 
Table 2. Mean intakes of nutrients and fluids, urine volume and p-aminobenzoic acid (PABA) recovery, and body weight in run-in, tea, and placebo periods, for sixty-five volunteers drinking black tea

(Mean values and standard deviations)

\begin{tabular}{|c|c|c|c|c|c|c|c|c|}
\hline \multirow[t]{2}{*}{ Test period ... } & \multicolumn{2}{|c|}{ Run-in } & \multicolumn{2}{|c|}{ Placebo } & \multicolumn{2}{|c|}{ Tea } & \multirow{2}{*}{$\begin{array}{c}\text { SD of } \\
\text { differences } \dagger\end{array}$} & \multirow{2}{*}{$\begin{array}{c}\text { Statistical } \\
\text { significance } \\
\text { of the } \\
\text { difference } \dagger \\
\text { tea } \nu \text {. } \\
\text { placebo: } P\end{array}$} \\
\hline & Mean & $\mathrm{SD}$ & Mean & SD & Mean & SD & & \\
\hline Energy (MJ) & $9 \cdot 37$ & 2.29 & 9.48 & $2 \cdot 39$ & 9.51 & $2 \cdot 23$ & 1.37 & 0.84 \\
\hline Protein $(\mathrm{g})$ & 81 & 21 & 83 & 22 & 85 & 22 & 13 & 0.20 \\
\hline Carbohydrate (g) & 259 & 75 & 262 & 75 & 260 & 70 & 46 & 0.71 \\
\hline Sugars $(g)$ & 111 & 49 & 114 & 53 & 111 & 46 & 39 & 0.43 \\
\hline Starch (g) & 110 & 34 & 140 & 39 & 142 & 41 & 17 & $0 \cdot 32$ \\
\hline NSP (g) & 14 & 5 & $13 \cdot 1$ & $5 \cdot 4$ & $13 \cdot 0$ & $5 \cdot 4$ & 1.6 & 0.68 \\
\hline Fat $(\mathrm{g})$ & 94 & 28 & 96 & 30 & 97 & 29 & 17 & 0.61 \\
\hline Monounsaturated fatty acids $(\mathrm{g})$ & 23 & 9 & 31 & 10 & 32 & 10 & 6 & 0.59 \\
\hline Saturated fatty acids $(\mathrm{g})$ & 33 & 10 & 36 & 14 & 37 & 13 & 8 & 0.41 \\
\hline Polyunsaturated fatty acids (g) & 50 & 41 & 16 & 5 & 16 & 6 & 3 & 0.40 \\
\hline Cholesterol (mg) & 228 & 86 & 236 & 99 & 246 & 101 & 61 & $0 \cdot 18$ \\
\hline Alcohol $(\mathrm{g})$ & 12 & 16 & 10 & 12 & 10 & 13 & 5 & 0.49 \\
\hline All drinks $(\mathrm{ml}) \ddagger$ & 2465 & 957 & 2776 & 751 & 2218 & 971 & 376 & 0.44 \\
\hline Tea $(\mathrm{ml}) \ddagger$ & 1445 & 985 & 0 & 0 & 1975 & 549 & - & - \\
\hline Urine volume $(\mathrm{ml}) \S$ & 1883 & 785 & 2135 & 838 & 2217 & 1021 & 738 & 0.67 \\
\hline PABA recovery $(\%) \S$ & 87 & 18 & 84 & 20 & 76 & 24 & 27 & 0.01 \\
\hline Urine volume $(\mathrm{ml}) \|$ & 1854 & 688 & 2125 & 766 & 2218 & 971 & 504 & 0.90 \\
\hline PABA recovery $(\%) \|$ & 88 & 14 & 84 & 17 & 76 & 21 & 23 & $<0.05$ \\
\hline No. of cigarettes smoked per d by smokers & $11 \cdot 2$ & $10 \cdot 5$ & $12 \cdot 4$ & $10 \cdot 4$ & $10 \cdot 8$ & 9.8 & 1.3 & $0 \cdot 10$ \\
\hline Body wt $(\mathrm{kg})$ & 69.4 & $11 \cdot 0$ & 68.9 & 10.7 & $69 \cdot 0$ & 10.8 & 0.7 & $>0.05$ \\
\hline Body wt (kg) excluding non-compliers ( $n 50)$ & $69 \cdot 0$ & $10 \cdot 6$ & $68 \cdot 7$ & $10 \cdot 3$ & 68.8 & $10 \cdot 3$ & 0.7 & 0.14 \\
\hline
\end{tabular}

* For details of subjects and procedures, see p. $42-46$ and Table 1.

$\dagger$ Paired $t$ test

$\ddagger$ Calculated from food diaries and drinks questionnaires on the day of collection.

$\S$ Values calculated from individual urine collections; values $>115 \%$ PABA excluded.

$\|$ Values $>115 \%$ PABA excluded; analyses for fifty-eight averages of two collections for the run-in period, fifty-three during the placebo period, and fifty-five during the tea period.

\section{Bowel habit}

Table 3 shows the reported frequency, consistency index, amount index and mean time spent per bowel movement throughout the study. The reported frequency of bowel movements per $14 \mathrm{~d}$ for all subjects ranged from 8 to 38 (18.5 (SD 6.5)), 7 to 42 (19.3 (SD $7.9)$ ) and 9 to $38(18.9$ (SD 7.1)) in the run-in, tea and placebo periods respectively. There were no significant differences between the tea and placebo periods, except that the consistency of specimens was significantly softer in the tea period compared with placebo period ( $P=0.041$ all subjects, $P=0.047$ excluding non-compliers).

\section{Blood pressure}

Diastolic blood pressures were significantly higher in the first week of the placebo period compared with the tea period: all subjects 72 (SD 10) $\mathrm{mm} \mathrm{Hg}$ tea, 76 (SD 11) $\mathrm{mm} \mathrm{Hg}$ placebo $(P=0.02)$; excluding non-compliers 72 (SD 10) $\mathrm{mm} \mathrm{Hg}$ tea, 76 (SD 11) $\mathrm{mm} \mathrm{Hg}$ 
Table 3. Mean values for bowel habit in the run-in, tea, and placebo periods, for sixty-five volunteers*, including and excluding fifteen non-compliers $\dagger$, drinking black tea

(Mean values and standard deviations)

\begin{tabular}{|c|c|c|c|c|c|c|c|c|}
\hline \multirow[t]{2}{*}{ Test period ... } & \multicolumn{2}{|c|}{ Run-in } & \multicolumn{2}{|c|}{ Placebo } & \multicolumn{2}{|c|}{ Tea } & \multirow{2}{*}{$\begin{array}{c}\text { SD of } \\
\text { differences }\end{array}$} & \multirow{2}{*}{$\begin{array}{c}\text { Statistical } \\
\text { significance } \\
\text { of difference } \\
\text { tea } v . \\
\text { placebo: } P\end{array}$} \\
\hline & Mean & SD & Mean & SD & Mean & SD & & \\
\hline \multicolumn{9}{|l|}{ All subjects $(n 65)$} \\
\hline Frequency (nos. of bowel movements per 2 weeks) & $18 \cdot 5$ & $6 \cdot 5$ & 18.9 & $7 \cdot 1$ & $19 \cdot 3$ & 7.9 & $4 \cdot 3$ & 0.44 \\
\hline $\begin{array}{l}\text { Consistency (values of } 1,2,3 \text { respectively assigned } \\
\text { to hard, soft, loose consistency) }\end{array}$ & 1.90 & 0.39 & 1.95 & 0.41 & 1.85 & 0.45 & 0.39 & 0.04 \\
\hline $\begin{array}{l}\text { Size (values of } 1,2,3 \text { respectively assigned to small, } \\
\text { medium, large) }\end{array}$ & $2 \cdot 31$ & 1.39 & 1.86 & 0.29 & 1.85 & 0.34 & 0.35 & 0.73 \\
\hline Time (min per bowel movement) & 3.63 & 3.00 & 3.67 & $3 \cdot 15$ & 3.49 & 3.0 & 0.89 & $0 \cdot 11$ \\
\hline \multicolumn{9}{|l|}{ Excluding non-compliers $(n$ 50) $\dagger$} \\
\hline Frequency (nos. of bowel movements per 2 weeks) & $17 \cdot 2$ & $5 \cdot 9$ & $17 \cdot 2$ & 5.8 & $17 \cdot 2$ & $6 \cdot 2$ & 3.48 & 0.87 \\
\hline $\begin{array}{l}\text { Consistency (values of } 1,2,3 \text { respectively assigned } \\
\text { to hard, soft, loose consistency) }\end{array}$ & 1.89 & $0 \cdot 35$ & 1.93 & 0.40 & 1.82 & 0.40 & $0 \cdot 38$ & $<0.05$ \\
\hline $\begin{array}{l}\text { Size (values of } 1,2,3 \text { respectively assigned } \\
\text { to small, medium, large) }\end{array}$ & $2 \cdot 21$ & 1.06 & 1.83 & 0.28 & 1.82 & 0.33 & 0.33 & 0.83 \\
\hline Time (min per bowel movement) & 3.62 & $3 \cdot 18$ & $3 \cdot 54$ & $3 \cdot 21$ & $3 \cdot 39$ & 3.06 & 0.91 & 0.27 \\
\hline
\end{tabular}

* For details of subjects and procedures, see pp. 42-46 and Table 1.

$\dagger$ Non-compliers were judged on the basis that the average marker, $p$-aminobenzoic acid, recovery was equivalent to less than four tea bags per $d$.

¥ Paired $t$ test.

placebo $(P=0.01)$. Systolic blood pressures were 118 (SD 14) $\mathrm{mm} \mathrm{Hg}$ tea, 121 (SD 17) $\mathrm{mm}$ $\mathrm{Hg}$ placebo in week $1(P=0.07)$ and were significantly different when values from noncompliers were excluded (118 (SD 14) $\mathrm{mm} \mathrm{Hg}$ tea, 122 (SD 18) $\mathrm{mm} \mathrm{Hg}$ placebo; $P=0.04$ ). However, there were no other significant differences when averages of weeks $2-4$ in tea and placebo periods were compared separately for all data and excluding non-compliers (data not shown). Table 4 shows that averaged values over the 4 -week period were not significantly different between tea and placebo periods in diastolic or systolic blood pressures, either when all subjects were included, or excluding non-compliers.

\section{Blood lipids}

Fig. 1 shows weekly mean values for total cholesterol in weeks 2,3 and 4 of the tea and placebo periods. No trends with time were evident. Total cholesterol was consistently lower in the tea period than in the placebo period in all weeks. However, these values were not significantly different between weeks, either when all values were included $(P=0.24$, $0.14,0.73$ for tea $v$. placebo in weeks 2,3 and 4 respectively), or when non-compliers were excluded $(P=0.30,0.34,0.86$ for tea $v$. placebo in weeks 2,3 and 4 respectively. The difference in total cholesterol in week 4 and run-in period was 0.024 (SE 0.106) mmol in the thirty-four subjects given tea first, and -0.03 (SE 0.12) mmol in the thirty-four subjects given tea second after the cross-over, and this difference was not significant (unpaired $t$ $0.04, P>0.05$ ).

Fig. 1 also shows that there were no evident time trends in LDL-cholesterol. The differences between tea and placebo periods were also not significant, either when all values were included $(P=0.21,0.45,0.55$ for tea $v$. placebo in weeks 2,3 , and 4 
Table 4. Mean values for blood pressure and lipids in run-in, tea, and placebo periods for sixtyfive volunteers*, including and excluding fifteen non-compliers $\dagger$, drinking black tea

(Mean values and standard deviations)

\begin{tabular}{|c|c|c|c|c|c|c|c|c|}
\hline \multirow[t]{2}{*}{ Test period ... } & \multicolumn{2}{|c|}{ Run-in } & \multicolumn{2}{|c|}{ Placebo } & \multicolumn{2}{|c|}{ Tea } & \multirow{2}{*}{$\begin{array}{c}\text { SD of } \\
\text { differences }\end{array}$} & \multirow{2}{*}{$\begin{array}{c}\text { Statistical } \\
\text { significance } \\
\text { of difference } \\
\text { tea } v \text {. } \\
\text { placebo: } P\end{array}$} \\
\hline & Mean & SD & Mean & SD & Mean & SD & & \\
\hline \multicolumn{9}{|l|}{ All subjects $(n$ 65) } \\
\hline Total cholesterol (mmol/l) & 5.67 & 1.05 & 5.76 & $1 \cdot 11$ & $5 \cdot 69$ & 1.09 & $0 \cdot 37$ & $0 \cdot 16$ \\
\hline HDL-cholesterol (mmol/l) & 1.48 & 0.42 & 1.52 & 0.44 & 1.49 & 0.44 & 0.15 & 0.19 \\
\hline LDL-cholesterol $(\mathrm{mmol} / \mathrm{l})$ & $3 \cdot 50$ & 1.29 & 3.53 & 1.32 & 3.48 & 1.29 & $0 \cdot 31$ & 0.20 \\
\hline Triacylglycerols (mmol/l) & 1.28 & 0.61 & 1.27 & 0.63 & $1 \cdot 28$ & $0 \cdot 65$ & $0 \cdot 31$ & 0.70 \\
\hline Systolic blood pressure $(\mathrm{mm} \mathrm{Hg})$ & 119.9 & $14 \cdot 0$ & $120 \cdot 1$ & 12.9 & 119.9 & $12 \cdot 7$ & 8.7 & 0.82 \\
\hline Diastolic blood pressure ( $\mathrm{mm} \mathrm{Hg}$ ) & $76 \cdot 6$ & 7.8 & $75 \cdot 1$ & 8.4 & 74.0 & 8.4 & $6 \cdot 3$ & 0.15 \\
\hline \multicolumn{9}{|l|}{ Excluding non-compliers (n 50) } \\
\hline Total cholesterol $(\mathrm{mmol} / \mathrm{l})$ & $5 \cdot 72$ & 1.03 & 5.75 & 1.08 & 5.70 & 1.06 & $0 \cdot 34$ & $0 \cdot 34$ \\
\hline HDL-cholesterol $(\mathrm{mmol} / \mathrm{l})$ & 1.47 & 0.43 & 1.50 & 0.44 & 1.49 & 0.44 & $0 \cdot 16$ & 0.49 \\
\hline LDL-cholesterol (mmol/1) & 3.60 & $1 \cdot 18$ & 3.60 & 1.20 & $3 \cdot 57$ & 1.17 & 0.28 & 0.47 \\
\hline Triacylglycerols (mmol/l) & 1.27 & 0.62 & $1 \cdot 30$ & 0.61 & $1 \cdot 31$ & 0.63 & 0.23 & 0.75 \\
\hline Systolic blood pressure $(\mathrm{mm} \mathrm{Hg})$ & $120 \cdot 5$ & 14.8 & $120 \cdot 2$ & $13 \cdot 6$ & $120 \cdot 0$ & 11.8 & $8 \cdot 3$ & 0.83 \\
\hline Diastolic blood pressure $(\mathrm{mm} \mathrm{Hg})$ & $75 \cdot 9$ & 7.9 & 74.5 & 8.6 & $72 \cdot 8$ & $8 \cdot 5$ & 7.4 & 0.12 \\
\hline
\end{tabular}

* For details of subjects and procedures, see pp. 42-46 and Table 1.

$\dagger$ Non-compliers were judged on the basis that the average marker, $p$-aminobenzoic acid, recovery was equivalent to less than four tea bags per $d$.

$\ddagger$ Paired $t$ test.

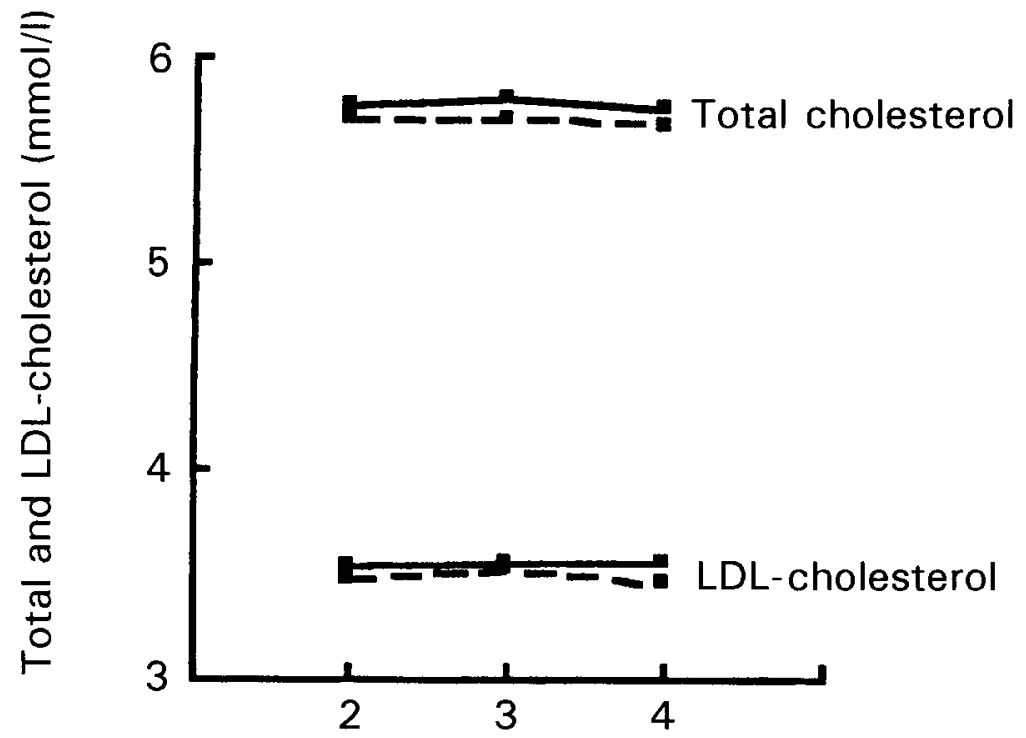

Week of tea or placebo periods

Fig. 1. Mean values for serum total and LDL-cholesterol (mmol/l) for weeks 2, 3, and 4 of the tea (---) and placebo $(\longrightarrow)$ periods for sixty-five volunteers drinking black tea. For details of subjects and procedures, see p. $42-46$ and Table 1. 


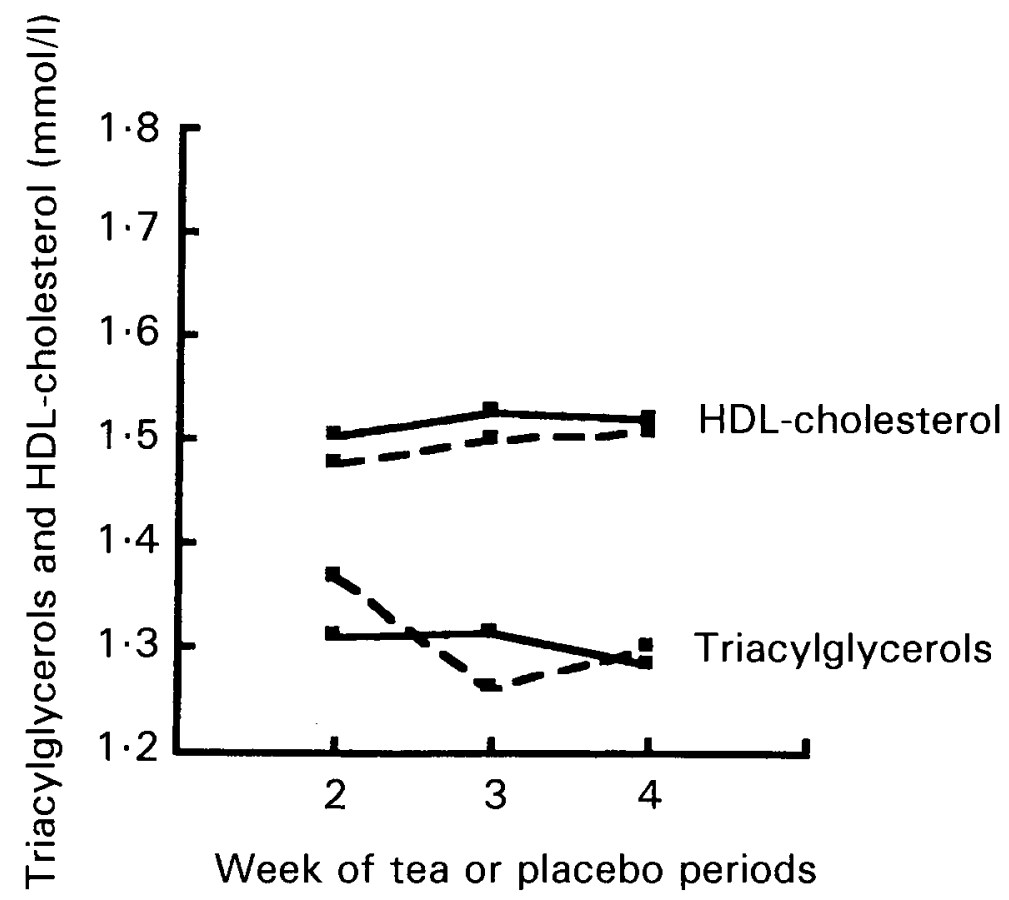

Fig. 2. Mean values for serum triacylglycerols and HDL-cholesterol ( $\mathrm{mmol} / \mathrm{l})$ for weeks 2, 3, and 4 of the tea (---) and placebo (-) periods for sixty-five volunteers drinking black tea. For details of subjects and procedures, see pp. $42-46$ and Table 1.

respectively) or when non-compliers were excluded $(P=0.26,0 \cdot 60,0.92$ for tea $v$. placebo in weeks 2, 3 and 4 respectively). Table 4 shows that averaged values over the 3 -week periods were not significantly different between tea and placebo periods in total or LDLcholesterol, either when all subjects were included, or when non-compliers were excluded. The difference in LDL-cholesterol between week 4 and the run-in period was 0.04 (SE 0.10 ) $\mathrm{mmol}$ in the thirty-four subjects given tea first, and 0.04 (SE 0.11 ) mmol in the thirtyone subjects given tea second after the cross-over, and this difference was not significant (unpaired $t 0.00, P>0.05$ ).

Fig. 2 shows weekly mean values for triacylglycerols and HDL-cholesterol in weeks 2 , 3 and 4 of the tea and placebo periods. No trends with time were evident. HDL-cholesterol was consistently lower in the tea period than in the placebo period for all weeks. However, these values were not significantly different between weeks, either when all values were included $(P=0.26,0.30,0.56$ for tea $v$. placebo in weeks 2,3 and 4 respectively), or when non-compliers were excluded $(P=0.44,0.81,0.56$ for tea $v$. placebo in weeks 2,3 and 4 respectively). The difference in HDL-cholesterol between week 4 and the run-in period was -0.01 (SE 0.03) mmol in the thirty-four subjects given tea first, and -0.04 (SE $0.03) \mathrm{mmol}$ in the thirty-one subjects given tea second after the cross-over, and this difference was not significant (unpaired $t 0.78, P>0.05$ ).

There were also no significant differences between weeks in the triacylglycerols values either when all values were included $(P=0.31,0.24,0.62$ for tea $v$. placebo in weeks 2,3 and 4 respectively) or when non-compliers were excluded $(P=0.27,0.36,0.92$ for tea $\nu$. placebo in weeks 2, 3 and 4 respectively). The difference in LDL-cholesterol between 
week 4 and the run-in period was 0.01 (SE 0.06) mmol in the thirty-four subjects given tea first, and 0.04 (SE 0.08) $\mathrm{mmol}$ in the thirty-one subjects given tea second after the crossover, and this difference was not significant (unpaired $t 0.38 P>0.05$ ). Table 4 shows that averaged values over the 3 -week periods were not significantly different between tea and placebo periods for triacylglycerols or HDL-cholesterol, either when all subjects were included, or when non-compliers were excluded.

\section{DISCUSSION}

Sixty-five individuals were recruited for the study, and comparisons with a national survey of adults (Gregory et al. 1990) suggest that the participants were fairly typical of the UK population, with no significant differences in serum cholesterol and blood pressure detected between the volunteers studied here and the national sample. For male participants, BMI were the same as those for the national sample, although the female participants were slightly taller and slimmer than in the national sample. These differences may reflect the younger age of the female participants ( 35 years) compared with that of the men ( 45 years) and with that of the national sample. The dietary intakes of the participants were also typical of the UK population, with a fat intake of $37 \%$ energy (national sample $38 \%$ ), although the intake of polyunsaturated fatty acids was higher than that consumed by the national sample. NSP intake of the men was $13-14 \mathrm{~g} / \mathrm{d}$, compared with the national average of about $12 \mathrm{~g} / \mathrm{d}$.

Compliance with the protocol was good, with only two participants of sixty-seven failing to complete the study. Sex, age, smoking, coffee consumption and initial cholesterol differences between subjects were avoided by using a randomized cross-over design for the study, with subjects acting as their own control. Lipid results were also analysed according to whether subjects were randomized to tea first, or second after cross-over, in order to assess whether there was an effect of carry-over. No effects were found. The placebo was matched not only for caffeine intake but also for milk, water and sugar consumption. No differences in dietary macronutrient intakes, including fatty acids, or dietary cholesterol were detected in the tea period $v$. placebo period. Similarly, no changes in smoking habit occurred throughout the study, although there was a slight $(0.2 \mathrm{~kg})$ increase in weight between tea and placebo periods. Tea consumption softened the reported consistency of specimens, but otherwise no changes occurred in bowel habit throughout the study, so that the reported constipating effects of tea drinking were not confirmed (Hojgaard et al. 1981; Magee, 1993).

In intervention trials of free-living individuals, a marker of compliance with the protocol, in this case tea drinking, is essential. Participants were asked to keep records of tea bags consumed throughout the test period, and the average reported consumption was 6.6 (SD 1.7) bags per $d$. All participants reported taking six bags per d but some took more than this, up to a maximum of thirteen bags per $d$. The individual who reported an even higher consumption of seventeen bags per day was, however, one of those categorized as a 'non-complier' by analysis of PABA in urine. Nevertheless, it is difficult to assess true compliance if reliance is placed on records or reports filled in by the subjects themselves, and, hence, we used urine volume and PABA as objective tests of tea-bag use. There were no significant differences in urine volume between the tea and placebo periods, and the volumes of 2.22 and 2.14 litres/d were high, and greater than those recorded in the run-in period of 1.8 litres/d. Average urine volume is 1.5 litres/d in the UK population (Bingham et al. 1988). Initial studies (Mulligan, 1993) demonstrated a linear relationship between the amount of PABA spotted onto tea bags and the amount recovered in urine, and so all $24 \mathrm{~h}$ 
urines should have contained the equivalent of the amount of PABA in six tea bags. However, collections from fifteen subjects contained the equivalent of less than four tea bags. This might have occurred because the collections were incomplete, or because less than six tea bags had been taken, or because care was not taken to follow the exact protocol when making tea so that less PABA was extracted, when less of the polyphenolics would also have been extracted. All these occurrences would suggest that a low recovery of PABA is indicative of less than perfect compliance with the study protocol, and for this reason results were analysed with and without data from these 15 'poor compliers'.

Total cholesterol, HDL-cholesterol, and LDL-cholesterol and triacylglycerols in blood and blood pressure were assessed in the present study in order to determine the effects of black tea on risk factors for CHD. Tea drinking may have had a small effect on total cholesterol, brought about by a reduction in both LDL- and HDL-cholesterol, but the difference of $0.07 \mathrm{mmol}(1 \%)$ in tea $v$. placebo cholesterol levels failed to reach significance at $P<0.05$. Within-person $\mathrm{CV}$ were predicted in order to calculate power at this level of significance, and the standard deviations of differences reported in Table 4 would indicate that the study size was sufficient for the level of power intended. However, the study was only designed to detect $5 \%$ differences in means, so that a real effect of tea on blood lipids cannot be ruled out on statistical grounds alone. If a real difference did exist, a $1 \%$ reduction in blood cholesterol would be associated with about a $2.5 \%$ reduction in risk of an acute coronary event in population terms (Holme, 1990). Some confidence in this view would have been possible had the differences between test and placebo become significant when results were considered without results from participants classified as 'non-compliers' However, this did not occur.

There are multiple risk factors for $\mathrm{CHD}$, with oxidant damage and thrombosis increasing risk, in addition to hyperlipidaemia and hypertension. Blood pressure was measured in the present study but no significant effect of tea drinking was seen. In the UK and Norway, tea drinking is not significantly associated with decreased risk of heart disease (Stensvold et al. 1992; Brown et al. 1993) nor with serum cholesterol in Israel (Kark et al. 1985), but an epidemiological study in the Netherlands has suggested that flavonoids, of which tea was a major source, were associated with a significantly decreased risk of mortality from CHD (Hertog et al. 1993). This effect was attributed to either the antioxidant properties of flavonoids, or to their inhibitory effect on cyclooxygenases and, hence, blood clotting (Laughton et al. 1991). Extracts of green tea have also been found to inhibit platelet thromboxane formation, and reduce blood coagulability (Ali \& Afzal, 1987; Lou et al. 1989). We also measured fibrinogen, plasminogen activator inhibitor, which decreases activation of plasminogen to plasmin by plasminogen activator, and plasminogen activator in the present study. We were unable to show any effect of black tea consumed with milk on these variables (Vorster et al. 1996). The addition of milk to tea may affect the absorption of tea polyphenols, since both green and black tea drunk without milk induce increased plasma antioxidant capacity, whereas black tea drunk with milk has no significant effect (Serafini et al. 1996). However, a later study has shown that black tea drunk without milk also has no effect on LDL resistance to oxidation, nor to serum lipids (K. H. van het Hof, H. S. M. de Boer, S. A. Wiseman, N. Lien, J. A. Weststrate \& L. B. M. Tijberg, unpublished results).

In conclusion, there is an accumulating body of evidence relating green tea consumption to cardiovascular disease risk. Nevertheless, despite our inclusion of measures to assess confounding by other dietary factors, and compliance with the study protocol, we were unable to establish significant effects of black tea drinking on risk factors measured here. 
The volunteers who took part in this study are thanked for their enthusiastic participation. Mrs Janet Beck is thanked for nursing expertise. Dr Tim Cole is thanked for statistical advice. This study was supported by the Tea Packers' Association.

\section{REFERENCES}

Ali, M. \& Afzal, M. (1987). A potent inhibitor of thrombin stimulated platelet thromboxane formation from unprocessed tea. Prostaglandins Leukotrienes and Medicine 27, 9-13.

Armitage, P. \& Berry, G. (1987). Statistical Methods in Medical Research, 2nd ed. Oxford: Blackwell Scientific Publications.

Bingham, S. A., Cassidy, A., Cole, T. J., Welch, A., Runswick, S. A., Black, A. E., Thurnham, D., Bates, C., Khaw, K. T., Key, T. J. A. \& Day, N. E. (1995). Validation of weighed records and other methods of dietary assessment using the $24 \mathrm{~h}$ urine nitrogen technique and other biological markers. British Journal of Nutrition $73,531-550$.

Bingham, S. A. \& Cummings, J. H. (1983). The use of 4-aminobenzoic acid as a marker to validate the completeness of 24 hour urine collections in man. Clinical Science 64, 629-635.

Bingham, S. A., Gill, C., Welch, A., Day, K., Cassidy, A., Khaw, K. T., Sneyd, M. J., Key, T. J. A., Roe, L. \& Day, N. E. (1994). Comparison of dietary assessment methods in nutritional epidemiology. British Journal of Nutrition 72, 619-643.

Bingham, S. A., Pett, S. \& Day, K. C. (1990). NSP intake of a random sample of British adults. Journal of Human Nutrition and Dietetics 3, 333-337.

Bingham, S., Williams, D. R. R., Cole, T. J., Price, C. P. \& Cummings, J. H. (1988). Reference values for analytes of $24 \mathrm{~h}$ urine collections. Annals of Clinical Biochemistry 25, 610-619.

Brown, C. A., Bolton-Smith, C., Woodward, M. \& Tunstall-Pedoe, H. (1993). Coffee and tea consumption and the prevalence of CHD in men and women. Journal of Epidemiology and Community Health 47, 171-175.

Crawley, H. (1988). Food Portion Sizes. London: H. M. Stationery Office.

Gardner, M. J. \& Heady, J. A. (1973). Some effects of within person variability in epidemiological studies. Journal of Chronic Diseases 26, 781-795.

Graham, G. (1992). Green tea composition, consumption and polyphenol chemistry. Preventive Medicine 21, 334-350.

Gregory, J., Foster, K., Tyler, H. \& Wiseman, M. (1990). The Dietary and Nutritional Survey of British Adults. London: H. M. Stationery Office.

Hara, Y. (1992). The effects of tea polyphenols on cardiovascular diseases. Preventive Medicine 21, 333A.

Hertog, M. G., Feskens, E. J. M., Hollman, P. C. H., Katan, M. B. \& Kromhout, D. (1993). Dietary antioxidants and risk of coronary heart disease. Lancet 342, 1007-1011.

Hojgaard, L., Arffman, S., Jorgensen, M. \& Krag, E. (1981). Tea consumption: a cause for constipation? British Medical Journal 282, 864 .

Holland, B., Unwin, I. D. \& Buss, D. H. (1988). Cereals and Cereal Products: Supplement to the 4th Edition of The Composition of Foods. Cambridge: Royal Society of Chemistry.

Holland, B., Unwin, I. D. \& Buss, D. H. (1989). Milk Products and Eggs: Supplement to the 4th Edition of the Composition of Foods. Cambridge: Royal Society of Chemistry.

Holland, B., Welch, A., Unwin, I. D., Buss, D. H., Paul, A. \& Southgate, D. A. T. (1991). McCance and Widdowson's The Composition of Foods, Sth ed. Cambridge: Royal Society of Chemistry.

Holme, I. (1990). An analysis of randomised trials on the effect of cholesterol reduction on total mortality and CHD incidence. Circulation 82, 1916-1924.

Ikeda, I., Imasato, Y., Sasaki, E., Nakayama, M., Nagao, H., Takeo, T., Yayabe, F. \& Sugano, M. (1992). Tea catechins decrease micellar solubility and intestinal absorption of cholesterol in rats. Biochimica et Biophysica Acta 1127, 141-146.

Imai, K. \& Nakachi, K. (1995). Cross sectional study of effects on drinking green tea on cardiovascular and liver diseases. British Medical Journal 310, 693-696.

Kark, J. D., Freidlander, Y., Kaufmann, N. A. \& Stein, Y. (1985). Coffee, tea and plasma cholesterol: the Jerusalem Lipid Research Clinic Prevalence Study. British Medical Journal 291, 699-704.

Laughton, M. J., Evans, P. J., Moroney, M. A., Hoult, J. R. D. S. \& Halliwell, B. N. A. (1991). Inhibition of mammalian 5-lipoxygenase and cyclooxygenase by flavonoids and phenolic dietary additives. Biochemical Pharmacology 42, 1673-1681.

Lawson, M., Fredricks, S. \& Johnson, A. (1991). The Hawksley random zero sphygmomanometer: unbiassed assessment of blood pressure in clinical trials? British Journal of Pharmacology 32, 647-650.

Lou, F. Q., Zhang, M. F., Zhang, X. G., Liu, J. M. \& Yaun, W. L. (1989). A study on tea pigment in prevention of atherosclerosis. Chinese Medical Journal 102, 579-583.

Magee, E. (1993). The effect of tea on bowel habit, measured by a diary and retrospective questionnaire. Industrial Placement Dissertation, University of Ulster, Coleraine. 
Matsuda, H., Chisaka, T., Kubomura, Y., Yamahar, J., Sawada, T., Fujimura, H. \& Kimura, H. (1986). Effects of crude tea on experimental hypercholesterolaemia. Journal of Ethnopharmacology 17, 213-224.

Mulligan, E. (1993). p-Amino benzoic acid as a monitor of compliance in intervention studies. Industrial Placement Dissertation, University of Ulster, Coleraine.

Muramatsu, K., Fukuyo, M. \& Hara, Y. (1986). Effect of green tea catechins on plasma cholesterol level in cholesterol fed rats. Joumal of Nutrition Science and Vitaminology 32, 613-622.

O'Brien, E., Mee, F., Atkins, N. \& O'Malley, K. (1990). Inaccuracy of the Hawksley random zero sphygmomanometer. Lancet 336, 1465-1468.

Paul, A. A. \& Southgate, D. A. T. (1978). McCance and Widdowson's The Composition of Foods, 4th ed. London: H. M. Stationery Office.

Serafini, M., Ghiselli, A. \& FerroLuzzi, A. N. A. (1996). In vivo antioxidant effect of green and black tea in man. European Journal of Clinical Nutrition 50, 28-32.

Silverman, K., Evans, S. M., Strain, E. C. \& Griffiths, R. R. (1992). Withdrawal symptoms after the double blind cessation of caffeine consumption. New England Journal of Medicine 327, 1109-1114.

Steinberg, D., Parthasarathy, S., Carew, T. E. \& Witztum, D. (1989). Beyond cholesterol: modifications of LDL that increase its atherogenicity. New England Journal of Medicine 320, 915-924.

Stensvold, I., Tverdal, A., Solvoll, K. \& Foss, O. P. (1992). Tea consumption: relationship to cholesterol, blood pressure and coronary and total mortality. Preventive Medicine 21, 546-553.

Systat (1990-2). Systat 5.2. Evanston, IL: Systat.

Vorster, H., Jerling, J., Oosthuizen, W., Cummings, J., Bingham, S., Magee, L., Mulligan, A. \& Runswick, S. (1996). Tea drinking and haemostasis: a randomised, placebo controlled, cross over study in free living subjects. Haemostasis 26, 58-64.

Wiles, S. J., Nettleton, P. A., Black, A. E. \& Paul, A. A. (1980). The nutrient content of some cooked dishes eaten in Britain: a supplementary food table. Journal of Human Nutrition 34, 189-223.

Yang, C. S. \& Wang, Z. (1993). Tea and cancer. Journal of the National Cancer Institute 85, 1038-1049. 